\title{
Effect of Dietary Fish Oil on Blood Levels of Free Fatty Acids, Ketone Bodies and Triacylglycerol in Humans
}

\author{
Pieter C. Dagnelie ${ }^{a, *, 1}$, Trinette Rietvelda ${ }^{a}$ G. Roelof Swart ${ }^{a}$, Theo Stijnen ${ }^{b}$ \\ and J. Willem O. van den Berga

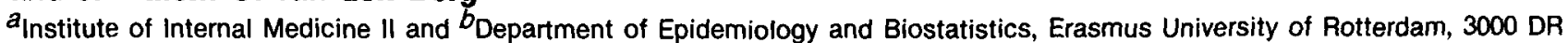 \\ Rotterdam, The Netherlands
}

\begin{abstract}
Although the reduction of serum triacylglycerol concentrations by dietary fish oil is a well-known effect, the exact mechanism of this effect has not been previously studied in human subjects. Therefore, the aim of this study was (i) to examine the effect of short-term fish oil supplementation on blood concentrations of ketone bodies, free fatty acids and triacylglycerol in healthy humans and (ii) to verify whether the observed relationships between these variables would be consistent with reduced lipolysis andlor enhanced hepatic fatty acid oxidation after fish oil supplementation. Twenty subjects (21-23 years, normal liver function tests) were randomly divided into two groups to supplement their usual diet with either $30 \mathrm{~g} / \mathrm{d}$ of fish oil ( $n=11)$ or olive oil $(n=9)$. Venous blood samples were drawn after an overnight fast, before and after 1, 3 and $7 \mathrm{~d}$ of fish oilolive oil supplementation. Blood concentrations of triacylglycerol and free fatty acids decreased consistently after fish oil supplementation; the reduction was already significant after one day of fish oil $(P<0.001$ for triacylglycerol and $\boldsymbol{P}=\mathbf{0 . 0 1}$ for free fatty acids). In contrast, neither of these blood values changed after olive oil supplementation $(P>0.10)$. No significant changes in glucose, insulin or ketone body levels were observed in either group after supplementation. After fish oil, but not after olive oil supplementation, the ratio of blood ketone body levels to free fatty acid levels increased significantly $(P<0.05)$. Furthermore, after fish oil supplementation only, free fatty acid levels were significantly correlated with levels of ketone bodies (day 7 of supplementation: $r$ $=0.90, P<0.001$ ) and triacylglycerol (maximum value on day 3: $r=0.77, P<0.01$ ). These findings suggest that reduced lipolysis and increased hepatic $\beta$-oxidation/ketogenesis may contribute to reduced triacylglycerol levels after $\omega \mathbf{3}$ fatty acid supplementation in humans. Turnover studies are needed in order to further quantitate these processes.
\end{abstract}

Lipids 29, 41-45 (1994).

The $\omega 3$ fatty acids eicosapentaenoic acid (EPA) and docosahexaenoic acid (DHA) in fish oil have aroused increasing interest over the past two decades because of their potential role in the prevention and treatment of cardiovascular disease $(1,2)$. One of the well-described effects of $\omega 3$ fatty acids from fish oil on humans is the reduction of serum triacylglycerol concentrations (3-7). The exact mechanism of this effect on humans is unknown. Animal studies have mainly focused upon the inhibitive effects of $\omega 3$ fatty acids on very low density lipoprotein (VLDL) formation and secre-

*To whom correspondence should be addressed at Institute of Internal Medicine II, Erasmus University of Rotterdam, P.O. Box 1738, 3000 DR Rotterdam, The Netherlands.

${ }^{\text {I} P . C . D . ~ i s ~ a ~ F e l l o w ~ o f ~ t h e ~ R o y a l ~ N e t h e r l a n d s ~ A c a d e m y ~ o f ~ A r t s ~ a n d ~}$ Sciences.

Abbreviations: CPT, carnitine palmitoyl transferase; DHA, docosahexaenoic acid; EPA, eicosapentaenoic acid; VLDL, very low density lipoprotein(s). tion $(8,9)$, especially triacylglycerol synthesis (10-15). Recently, it was suggested that a slower formation of plasma VLDL triacylglycerols in rats fed fish oil may be due to a faster rate of hepatic fatty acid oxidation (16). There are also recent animal data suggesting that $\omega 3$ fatty acids may reduce lipolysis from adipose tissue, thus limiting the availability of free fatty acids as a substrate for hepatic triacylglycerol formation $(17,18)$.

Although the ultimate goal of animal studies is to gain insight into potential mechanisms of the action of $\omega 3$ fatty acids in humans, no human studies on the effect of $\omega 3$ fatty acids on lipolysis and ketone body production have been reported so far. Therefore, the aim of the present study was to investigate the effects of dietary fish oil on blood levels of free fatty acids, ketone bodies and triacylglycerol in healthy human subjects, and to verify whether the observed relationships between these variables would be consistent with reduced lipolysis and/or enhanced hepatic fatty acid oxidation after fish oil supplementation.

\section{MATERIALS AND METHODS}

Subjects and study design. The study protocol was approved by the Research Ethics Committee of the University Hospital of Rotterdam, and written informed consent was obtained from all subjects prior to the study. Eligible for the study were healthy medical students aged 21-23 yr who were on normal, nonslimming diets with, at most, one meal of fish per week. All subjects had normal liver function tests and took no fish from one week prior to the study and throughout. Twenty-two subjects were randomly distributed over an experimental and a placebo group in a double-blinded fashion. Two subjects from the placebo group did not show up on the first day of the study, leaving eleven subjects in the experimental group and nine in the placebo group. Subjects in the experimental group took $30 \mathrm{~g}$ of MaxEPA fish oil per day, containing a total of $9 \mathrm{~g} \omega 3$ fatty acids per day (EPA, 5.4 $\mathrm{g} / \mathrm{d}$; DHA, $3.6 \mathrm{~g} / \mathrm{d}$ ) for $7 \mathrm{~d}$. Subjects in the placebo group took $30 \mathrm{~g}$ of olive oil per day during the same period. Capsules of fish oil and olive oil (indistinguishable by addition of peppermint oil and ferrous oxide coloring) were kindly provided by Seven Seas Ltd. (Hull, United Kingdom), and taken as $3 \times 10$ capsules per day with the main meals.

Measurements. Following an overnight fast of approximately $12 \mathrm{~h}$, subjects came to the laboratory between 8 and 9 a.m., before (day 0) and after supplementation (days 1,3 and 7). On these days, subjects were weighed, and venous blood samples were drawn from the forearm. Height was measured once preceding the study.

Laboratory analyses. Glucose concentrations in whole blood were determined by an enzymatic assay using an Epos 5060 analyzer (Merck-Eppendorf, Darmstadt, Germany) with reagents from Boehringer (Mannheim, Germany). Triacylglycerol in serum was determined enzymatically on a Chem-1 analyzer (Bayer-Technicon, 
P.C. DAGNELIE ET $A L$.

Tarrytown, New York). Free fatty acids were determined in ethylenediaminetetraacetic acid-treated plasma using an enzymatic colorimetric method (NEFA C test kit; Wako Chemicals, Neuss, Germany). A conversion factor of 0.282 was used (derived from the molecular weight of oleic acid) for conversion of these values (from $\mu \mathrm{mol} / \mathrm{L}$ into $\mathrm{mg} / \mathrm{L}$ ). For determination of ketone bodies in whole blood, $4 \mathrm{~mL}$ of blood was poured immediately into a glass bottle containing $4 \mathrm{~mL}$ ice-cold perchloric acid, and, after neutralization with $\mathrm{KOH}(19)$, stored at $-20^{\circ} \mathrm{C}$ until the study was completed. Acetoacetate and $\beta$-hydroxybutyrate concentrations were determined according to Mellanby and Williamson (19) and Williamson and Mellanby (20), respectively. Insulin in serum was determined using a commercial radioimmunoassay test kit (Medgenix, Brussels, Belgium).

Compliance. For each subject, the number of capsules taken per day was calculated by pre- and post-weighing supplied capsules, and used as an indicator of compliance.

Statistical analysis. Blood values are expressed as means \pm SEM, except for free fatty acids, ketone bodies and the ketone body/free fatty acid ratio. As the latter showed a skewed distribution which best fitted normal distribution after log-transformation, log-transformed data were used for statistical calculations of these parameters, and data for these parameters are presented as geometrical means and range. Changes in blood values within one group were tested for statistical significance using Student's paired $t$-test. Comparison of the effects of fish oil $v s$. olive oil supplementation on blood values was tested after adjustment for baseline values by analysis of covariance. Mean values and 1, 3 and $7 \mathrm{~d}$ of supplementation were used for the previously mentioned statistical calculations. For comparing residual variances between groups, the standard F-test was used (21). Changes in residual standard deviation after supplementation within one group were tested by 11 "repeated measurements analysis of variance" using module $5 \mathrm{~V}$ of BMDP (22). $P$ values less than 0.05 were considered statistically significant.

\section{RESULTS}

Anthropometric measurements. Baseline values of body weight and height were similar in the fish oil group and the olive oil group. The quetelet index was $21.7 \pm 0.6$ $\mathrm{kg} / \mathrm{cm}^{2}$ (mean $\pm \mathrm{SEM}$ ) in the fish oil group and $22.5 \pm$ $1.3 \mathrm{~kg} / \mathrm{cm}^{2}$ in the olive oil group. No relation between quetelet index and baseline values of any of the measured blood parameters was detected. No significant changes in weight were observed in either group during the study (fish oil group, $0.2 \pm 0.1 \mathrm{~kg}$; olive oil group, -0.5 $\pm 0.3 \mathrm{~kg}$ ).

Compliance. Participants had been instructed to take $30 \mathrm{~g}$ of the provided supplement per day. The estimated "actual" intake ranged from $29-31 \mathrm{~g} / \mathrm{d}$ in the fish oil group and from 29-32 $\mathrm{g}$ in the olive oil group, indicating good compliance.

Blood values. Blood glucose and insulin concentrations did not change systematically after fish or olive oil supplementation (Table 1). Triacylglycerol concentrations decreased by $24 \%(P<0.001)$ within $1 \mathrm{~d}$ of fish oil supplementation. After $7 \mathrm{~d}$ of fish oil supplementation, triacylglycerol had decreased by $46 \%(P<0.001)$, as compared to baseline (Table 1). Olive oil supplementation had no significant effect on triacylglycerol levels $(P>0.10$; Table 1). The effects of fish oil and olive oil supplementation on triacylglycerol levels were significantly different $(P=0.001)$.

Free fatty acid concentrations decreased by $39 \%(P=$ $0.01)$ within $1 \mathrm{~d}$ of fish oil supplementation and remained significantly depressed at 3 and $7 \mathrm{~d}$ of supplementation for each $(P<0.05$ as compared to baseline; Table 2$)$. In contrast, no significant change in free fatty acid levels was observed after olive oil supplementation $(P>0.10)$. The effects of fish oil and olive oil supplementation on free fatty acid levels were significantly different $(P=0.03)$. No significant changes in ketone body levels were observed after either fish oil or olive oil supplementation $(P>0.10$; Table 2).

\section{TABLE 1}

Blood Values of Glucose, Insulin and Triacylglycerol in Healthy Human Subjects Before and After Dietary Supplementation with Fish Oil or Olive $\mathrm{Oil}^{\alpha}$

\begin{tabular}{|c|c|c|c|c|c|c|}
\hline & \multirow[b]{2}{*}{$\begin{array}{c}\text { Before } \\
\text { supplementation }\end{array}$} & \multicolumn{3}{|c|}{ After supplementation for } & \multicolumn{2}{|c|}{$P$ value } \\
\hline & & $1 \mathrm{~d}$ & $3 \mathrm{~d}$ & $7 \mathrm{~d}$ & $\begin{array}{c}\text { Change within } \\
\text { groups }^{b}\end{array}$ & $\begin{array}{l}\text { Change compared } \\
\text { between groups }{ }^{c}\end{array}$ \\
\hline \multicolumn{7}{|l|}{ Glucose $(\mathrm{mmol} / \mathrm{L})$} \\
\hline Fish oil group & $4.2 \pm 0.1$ & $4.3 \pm 0.1$ & $4.3 \pm 0.1$ & $4.0 \pm 0.1$ & $\mathrm{NS}^{d}$ & \multirow[t]{2}{*}{ NS } \\
\hline \multirow{2}{*}{\multicolumn{7}{|c|}{ Insulin (pmol/L) }} \\
\hline & & & & & & \\
\hline Fish oil group & $102 \pm 9$ & $104 \pm 11$ & $84 \pm 10$ & $97 \pm 13$ & NS & \multirow[t]{2}{*}{ NS } \\
\hline Olive oil group & $121 \pm 12$ & $97 \pm 10$ & $92 \pm 9$ & $99 \pm 9$ & NS & \\
\hline \multicolumn{7}{|c|}{ Triacylglycerol (mmol/L) } \\
\hline Fish oil group & $0.96 \pm 0.08$ & $0.73 \pm 0.06$ & $0.64 \pm 0.05$ & $0.61 \pm 0.06$ & $<0.001$ & \multirow{2}{*}{0.001} \\
\hline Olive oil group & $1.04 \pm 0.17$ & $0.98 \pm 0.13$ & $1.04 \pm 0.10$ & $1.07 \pm 0.14$ & NS & \\
\hline
\end{tabular}

${ }^{a}$ Healthy human subjects were randomized to take a daily supplement of either $30 \mathrm{~g}$ fish oil (9 $\mathrm{g} \omega 3$ fatty acids; $\left.\mathrm{n}=11\right)$ or $30 \mathrm{~g}$ olive oil $(\mathbf{n}=9)$ for $7 \mathrm{~d}$. Each figure represents the arithmetic mean $\pm \mathrm{SEM}$.

${ }^{b}$ Paired $t$-test (mean value of 1,3 and $7 \mathrm{~d}$ of supplementation $v s$. baseline value).

${ }^{c}$ Effects of fish oil $v s$. olive oil supplementation were tested using mean values of 1,3 and $7 \mathrm{~d}$ of supplementation, adjusting for baseline values by analysis of covariance.

${ }^{d}$ NS, not significant. 
TABLE 2

Blood Values of Free Fatty Acids and Ketone Bodies in Healthy Human Subjects Before and After Dietary Supplementation with Fish Oil or Olive Oil ${ }^{a}$

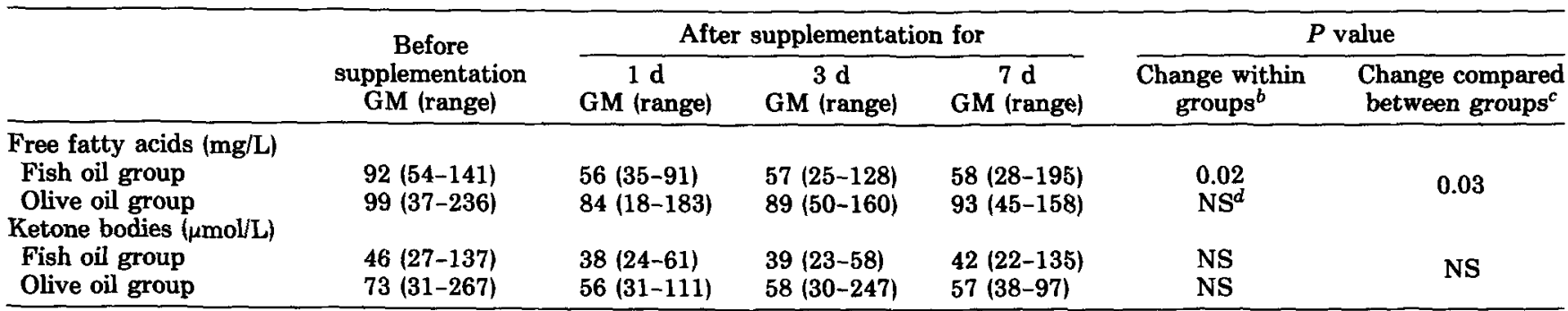

aStudy design: see footnote a to Table 1. Each figure represents the geometrical mean (GM) and range.

${ }^{5}$ Paired $t$-test (mean value of 1,3 and $7 \mathrm{~d}$ of supplementation $v s$. baseline value).

${ }^{c}$ Effects of fish oil $v s$. olive oil supplementation were tested using mean values of 1,3 and $7 \mathrm{~d}$ of supplementation, adjusting for baseline values by analysis of covariance.

${ }^{d}$ S, not significant.

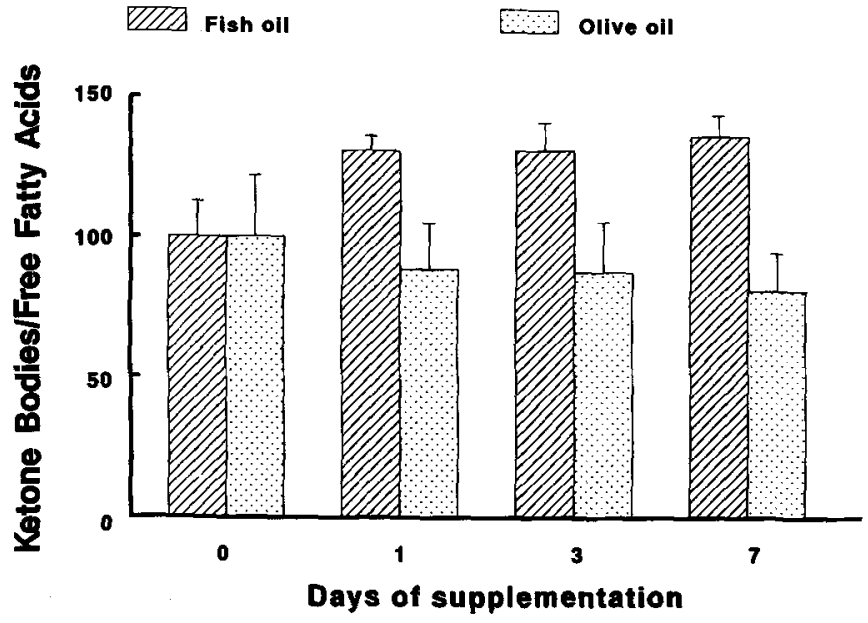

FIG. 1. Ratios of blood ketone body concentrations to plasma free fatty acids before and after 1,3 and $7 \mathrm{~d}$ of fish oil or olive oil supplementation. Healthy human subjects took a daily supplement of either $30 \mathrm{~g}$ fish oil ( $9 \mathrm{~g} \omega 3$ fatty acids; $\mathrm{n}=11$ ) or $30 \mathrm{~g}$ olive oil ( $\mathrm{n}$ $=9$ ). Boxes and bars represent means and SEM, respectively, of logarithmic values (expressed as a percentage of values before supplementation). Significance of change after fish oil supplementation (paired $t$-test of mean value of 1,3 and $7 \mathrm{~d}$ of supplementation $v 8$. baseline value), $P<0.05$; olive oil supplementation, $P>0.10$. Comparison of the effects of fish oil vs. olive oil supplementation (mean values of 1,3 and $7 \mathrm{~d}$ of supplementation, adjusting for baseline values by analysis of covariance), $P=0.02$.

Ratios of ketone body levels relative to free fatty acid levels (Fig. I) increased significantly after fish oil supplementation $(P<0.05)$, but did not change after olive oil supplementation $(P>0.10)$. Again, the effects of fish oil and olive oil supplementation were significantly different $(P=0.02)$.

In Figure 2, ketone bodies are plotted as a function of free fatty acids before and after seven days of supplementation with fish oil or olive oil. No significant correlation between free fatty acid levels and ketone body concentrations was observed in either group before supplementation, or after olive oil supplementation $(P>0.10)$. In contrast, these two parameters were highly correlated after seven days of fish oil supplementation $(r=0.90$, $P<0.001$ ). The residual standard deviation of blood ketone body levels against free fatty acid levels was con-

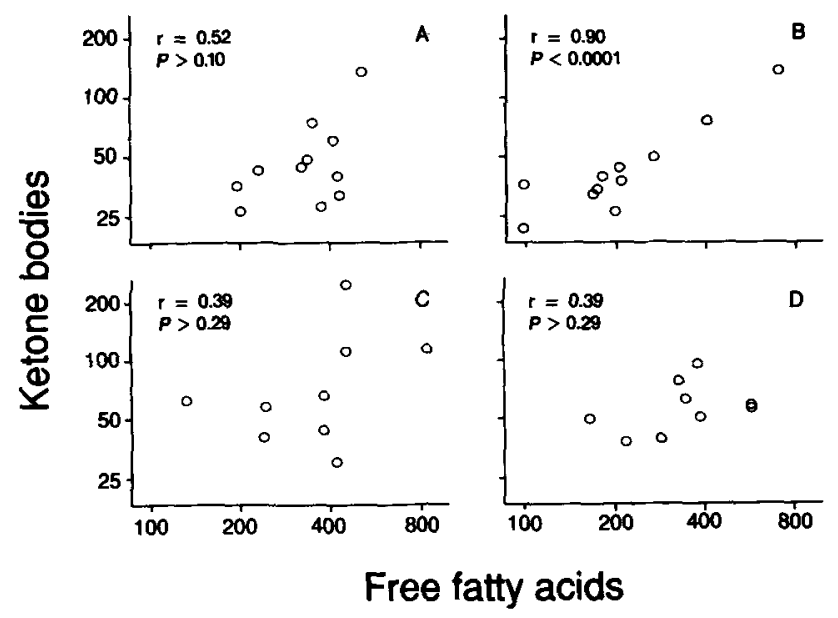

FIG. 2. Blood ketone body concentrations ( $\mu \mathrm{mol} / \mathrm{L})$ as a function of plasma free fatty acid concentrations $(\mu \mathrm{mol} / \mathrm{L})$ before and after supplementation with fish or olive oil; (A) before fish oil supplementation, (B) after $7 \mathrm{~d}$ of fish oil supplementation, (C) before olive oil supplementation, (D) after $7 \mathrm{~d}$ of olive oil supplementation. The methods used are those given in the caption for Figure 1.

sistently reduced after seven days of fish oil supplementation $(P \leqslant 0.01)$, and residual standard deviation was significantly lower after fish oil supplementation than after olive oil supplementation (day $7: P<0.001$ ). As the total variation in ketone body levels did not increase after fish oil supplementation ('Table 2 and Fig. 2), the increase in correlation between free fatty acid and ketone body levels after fish oil supplementation (and the difference in correlation when compared with olive oil supplementation) was exclusively attributed to a reduction in residual standard deviation after fish oil supplementation.

Free fatty acid levels were not significantly correlated with triacylglycerol concentrations in either group before supplementation or after olive oil supplementation $(P>0.10)$. An increased correlation was observed after seven days of fish oil supplementation which, however, did not reach statistical significance $(r=0.52 ; P=0.10$ ). After three days of fish oil supplementation, the correlation between free fatty acid and triacylglycerol levels was highly significant $(\mathrm{r}=0.77, P<0.01)$. 


\section{DISCUSSION}

Although it is well known that marine $\omega 3$ fatty acids reduce serum triacylglycerol concentrations in humans (3-7), the mechanism underlying this effect is not completely understood. Most of the effects described so far, observed in animal models in vivo and in vitro, were related to reduced production and secretion of triacylglycerol-rich lipoproteins (VLDL) by the liver. Effects of $\omega 3$ fatty acids on nearly every major pathway of hepatic fatty acid metabolism have been demonstrated. Reduction of triacylglycerol synthesis by $\omega 3$ fatty acids has been attributed to reduced activities of phosphatidate phosphohydrolase $(10,11)$ and acyl-coenzyme A:1,2-diacylglycerol acyltransferase $(12,23)$, and to a diversion toward phospholipid synthesis $(13-15,24)$. At high dosage of $\omega 3$ acids, an inhibition of VLDL assembly and/or secretion has been reported (9).

A number of animal studies have also demonstrated increased hepatic $\beta$-oxidation capacity and ketone body production after fish oil feeding $(11,24-30)$. Surette et al. (31) observed an increased activity of hepatic carnitine palmitoyltransferase (CPT) in fish oil-fed Syrian hamsters, which was highly correlated $(r=-0.97)$ with the dietinduced change in serum triacylglycerol levels. Wong et al. (25) observed a decreased sensitivity of mitochondrial CPT to inhibition by malonyl-CoA.

Recently, attention has been drawn to the possibility that fish oil decreases peripheral lipolysis from adipose tissue, thereby reducing the availability of substrate for triacylglycerol synthesis in the liver $(17,18,27)$. The activities of lipoprotein lipase and hepatic lipase, enzymes which are involved in VLDL catabolism, are unaffected by fish oil supplementation (6).

Because there is little information about these processes in humans, a randomized, placebo-controlled study on the effects of fish oil supplementation on blood values of free fatty acids, ketone bodies and triacylglycerol, and the relationship between these blood values was carried out. Results demonstrate that fish oil supplementation induced a rapid parallel reduction in blood concentrations of triacylglycerol and free fatty acids, whereas ketone body levels remained constant. Changing blood values were not due to increased fat consumption per se, because supplementation with placebo (olive oil) did not affect either free fatty acid or triacylglycerol levels.

Although the reduction in free fatty acid levels after fish oil supplementation has not been systematically studied in healthy human subjects, Singer et al. (17) recently reported that dietary supplementation with $\omega 3$ fatty acids resulted in a marked decrease in free fatty acid levels during a standard glucose tolerance test in hyperlipidemic patients. Otto et al. (18) observed a dose-dependent reduction in plasma free fatty acids by $\omega 3$ fatty acids in rats fed ad libitum, but not in rats fasted overnight. Since insulin concentration were constant and glucose concentrations increased, the authors (18) concluded that lower plasma free fatty acid levels could not be explained by either increased insulin concentrations or improved insulin sensitivity of adipose tissue. Preliminary data from another recent study (32) in rats fed marine $\omega 3$ fatty acids confirmed a marked reduction in free fatty acid levels. In addition, a significant reduction of fatty acid mobilization from epididymal adipocytes of these rats was demon- strated (32). Our finding of reduced blood values of free fatty acids in spite of constant glucose and insulin levels after fish oil supplementation is consistent with these recent reports.

In their studies with rats, Otto et al. (18) observed a positive correlation ( $r=0.71$ ) between blood values of free fatty acids and triacylglycerol. A similar correlation $(\mathbf{r}=$ 0.77 ) was observed in the present study after three days of fish oil supplementation. This would suggest that the lowering of plasma free fatty acids by dietary fish oil may have contributed to the decrease in serum triacylglycerol levels.

In spite of the decrease in plasma free fatty acid levels after fish oil supplementation, we did not detect any significant changes in blood ketone body levels. As a consequence, the ratio of ketone bodies to free fatty acids increased significantly after fish oil supplementation. It is unlikely that this was caused by decreasing ketone body removal from the blood, as ketone body uptake by peripheral tissues is thought to be controlled by the ketone body concentrations presented to them (33,34). Arterial ketone body levels closely reflect hepatic ketone body production (35). Therefore, the increased ratio of ketone bodies to free fatty acids, combined with the markedly high correlation $(r=0.90)$ between these blood values after fish oil supplementation, suggests an increased capacity for fatty acid oxidation and/or ketogenesis in the liver. This suggestion is consistent with animal studies that demonstrated increased $\beta$-oxidation and ketogenesis by dietary $\omega 3$ fatty acids $(11,24-31)$.

If increased hepatic $\beta$-oxidation and ketogenesis would not be counteracted by reduced lipolysis from adipose tissue, ketosis would occur (36). It is speculated that the combination of decreased lipolysis and increased capacity or hepatic $\beta$-oxidation/ketogenesis may be a concerted mechanism whereby fish oil reduces triacylglycerol formation in the liver without, however, simultaneously inducing ketosis.

In conclusion, our study shows that dietary fish oil, in addition to its well-known effect of reducing serum triacylglycerol concentrations, induces a rapid reduction in blood free fatty acids, and a parallel rise in the ratio of ketone bodies relative to free fatty acids. These effects appear not to be due to changes in insulin concentration or sensitivity, and because they occur within one day of supplementation, they are unlikely to be related to altered membrane composition by $\omega 3$ fatty acids. Our findings are consistent with the notion that reduced lipolysis and increased hepatic $\beta$-oxidation/ketogenesis may contribute to reduced triacylglycerol levels after $\omega 3$ fatty acid supplementation in humans. Turnover studies are needed in order to provide further quantitation of these processes.

\section{ACKNOWLEDGMENTS}

The authors are grateful to M.P.M. de Maat, M.J. Gomes, L.J. Perret, J. Francke and P. Uitterlinden (Academic Hospital RotterdamDijkzigt, Departments of Internal Mecine II, Internal Medicine III, Hematology, and Clinical Chemistry) for technical assistance. We also would like to thank Drs. J.D. Bell and M.L. Barnard, (NMR Unit/Department of Endocrinology and Metabolism, Royal Postgraduate Medical School, Hammersmith Hospital, London, United Kingdom) for participation in previous pilot experiments leading to the present study. 


\section{REFERENCES}

1. Simopoulos, A.P. (1991) Am. J. Clin. Nutr. 54, 438-463.

2. Harris, W.S. (1989) J. Lipid Res. 30, 785-807.

3. Harris, W.S., Rothrock, D.W., Fanning, A., Inkeles, S.B., Goodnight, S.H., Illingworth, D.R., and Connor, W.E. (1990) Am. J. Clin. Nutr. 51, 399-406.

4. Stacpoole, P.W., Alig, J., Ammon, L., and Crockett, S.E. (1989) Metabolism 38, 946-956.

5. DeLany, J.P., Vivian, V.M., Snook, J.T., and Anderson, P.A. (1990) Am. J. Clin Nutr. 52, 477-485.

6. Nozaki, S., Garg, A., Lena Vega, G., and Grundy, S.M. (1991) Am. J. Clin. Nutr. 53, 638-642.

7. Annuzzi, G., Rivellese, A., Capaldo, B., Di Marino, L., Iovine, C., Marotta, G., and Riccardi, G. (1991) Atherosclerosis 87, 65-73.

8. Nestel, P.J., Conner, W.E., Reardon, M.F., Connor, S., Wong, S., and Boston, R. (1984) J. Clin. Invest. 74, 82-89.

9. Lang, C.A., and Davis, R.A. (1990) J. Lipid Res, 31, 2079-2086.

10. Wong, S.H., and Marsh, J.B. (1987) Metabolism 37, 1171-1181.

11. Halminski, M.A., Marsh, J.B., and Harrison, E.H. (1991) J. Nutr. $121,1554-1561$.

12. Rustan, A.C., Nossen, J.O., Christiansen, E.N., and Drevon, C.A. (1988) J. Lipid Res. 29, 1417-1426.

13. Benner, K.G., Sasaki, A., Gowen, D.R., Weaver, A., and Connor, W.E. (1990) Lipids 25, 534-540.

14. Parks, J.S., Johnson, F.L., Wilson, M.D., and Rudel, L.L. (1990) J. Lipid Res. 31, 455-466.

15. Yeo, Y.K., and Holub, B.J. (1990) Lipids 25, 811-814.

16. Lottenberg, A.M.P., Oliveira, H.C.F., Nakandakare, E.R., and Quintao, E.C.R. (1992) Lipids 27, 326-330.

17. Singer, P., Wirth, M, and Berger, I. (1990) Atherosclerosis 83, $167-175$.

18. Otto, D.A., Baltzell, J.K., and Wooten, J.T. (1992) Lipids 27, 1013-1017.

19. Mellanby, T., and Williamson, D.H. (1974) in Methods of Enzymatic Analysis (Bergmeyer, H.O., ed.) Vol. 4, 2nd edn., pp. 1840 1843, Verlag Chemie, Weinheim/Academic Press, New York.
20. Williamson, D.H., and Mellanby, T. (1974) in Methods of Enzymatic Analysis (Bergmeyer, H.O., ed.) Vol. 4, 2nd edn., pp. 1836-1839, Verlag Chemie, Weinheim/Academic Press, New York.

21. Armitage, P., and Berry, G. (1987) Statistical Methods in Medical Research, 2nd edn., Blackwell, Oxford.

22. Schluchter, M.D. (1990) in BMDP Statistical Software Manual, Vol. 2, (Dixon, W.J., ed.) pp. 1207-1244, University of California Press, Berkeley.

23. Rustan, A.C., and Drevon, C.A. (1989) J. Internal Med. 225 (Suppl 1), 31-38.

24. Zhang, Z.J., Wilcox, H.G., Elam, M.B., Castellani, L.W., and Heimberg, M. (1991) Lipids 26, 504-511.

25. Wong, S.H., Nestel, P.J., Trimble, R.P., Storer, G.B., Illman, R.J., and Topping, D.L. (1984) Biochim. Biophys. Acta 729, 103-109.

26. Bergseth, S., Christiansen, E.N., and Bremer, J. (1986) Lipids $21,508-514$

27. Illman, R.J., Trimble, R.P., Storer, G.B., Topping, D.L., and Oliver, J.R. (1986) Atherosclerosis 59, 313-321.

28. Marsh, J.B., Tbpping, D.L., and Nestel, P.J. (1987) Biochim. Biophys. Acta 922, 239-243.

29. Topping, D.L., Trimble, R.P., and Storer, G.B. (1987) Biochim. Biophys. Acta 927, 423-428.

30. Brady, P.S., Marine, K.A., Brady, L.J., and Ramsay, R.R. (1989) Biochem. J. 260, 93-100.

31. Surette, M.E., Whelan, J., Broughton, K.S., and Kinsella, J.E. (1992) Biochim. Biophys. Acta 1126, 199-205.

32. Drevon, C.A., Hustvedt, B.E., and Rustan, A.C. (1992) Program and Abstracts of the Third International Congress on Essential Fatty Acids and Eicosanoids. Adelaide, Australia, p. 46.

33. Rich, A.J. (1990) Proc. Nutr. Soc. 49, 361-373.

34. Williamson, D.H. (1971) Postgrad. Med. J. 47, (Suppl.) 371-375.

35. Havel, R.J., Kane, J.P., Balasse, E.O., Segel, N., and Basso, L.V. (1970) J. Clin. Invest. 49, 2017-2035.

36. McGarry, J.D., and Foster, D.W. (1977) Arch. Intern. Med. 137, 495-501.

[Received February 27, 1993; Revision accepted October 13, 1993] 